\title{
Immunomodulatory Effects of Macrolide Antibiotics - Part 2: Advantages and Disadvantages of Long-Term, Low-Dose Macrolide Therapy
}

\author{
J. Altenburg ${ }^{a} \quad$ C.S. de Graaffa $\quad$ T.S. van der Werf ${ }^{b} \quad$ W.G. Boersma ${ }^{a}$ \\ a Department of Pulmonary Diseases, Medical Centre Alkmaar, Alkmaar, and ${ }^{\text {b }}$ Department of Internal Medicine, \\ University Medical Centre Groningen, University of Groningen, Groningen, The Netherlands
}

\section{Key Words}

Diffuse panbronchiolitis · Cystic fibrosis $\cdot$ Macrolides

\begin{abstract}
The available evidence for long-term, low-dose treatment with 14- and 15-membered ring macrolides in non-cystic fibrosis (CF) bronchiectasis, COPD, chronic sinusitis, and asthma is reviewed with special attention to possible adverse effects and the emergence of resistance during long-term macrolide treatment. Macrolide maintenance therapy has been proven to be of benefit in diffuse panbronchiolitis and CF, presumably due to an anti-inflammatory mechanism of action in addition to its direct antimicrobial effect. Solid evidence to justify this treatment regimen for non-CF bronchiectasis, asthma, or sinusitis is still lacking, although a beneficial effect of long-term macrolide therapy has been found in small clinical trials on these subjects. Data from randomized trials of long-term macrolide treatment in COPD are conflicting. A sufficiently long duration of treatment and the careful selection of patients appears to be crucial. Aside from its beneficial effects, possible side effects of macrolide treatment should be taken into account, the most important of these being gastrointestinal upset and cardiac arrhythmias. Development of macrolide resistance among respiratory pathogens is very common during long-term macrolide treatment. Whether this finding is clinically significant is a matter of debate.

Copyright $\odot 2010$ S. Karger AG, Basel
\end{abstract}

\section{Introduction}

In pulmonary practice, prolonged macrolide therapy with reduced dosages has become increasingly popular for the treatment of patients with chronic inflammatory conditions, such as non-cystic fibrosis (CF) bronchiectasis and sinusitis, who have recurrent infections or other signs of 'badly regulated disease'. In this article we aim to provide an overview of the available evidence for macrolide maintenance therapy in these chronic inflammatory pulmonary conditions.

The concept of treating inflammatory lung diseases with macrolide maintenance therapy originated in Japan where, in 1987, Kudoh et al. [1] reported a spectacular decrease in symptoms and increase in life expectancy in patients with diffuse panbronchiolitis (DPB) following treatment with the macrolide erythromycin (EM). Until then, $\mathrm{DPB}$ had been a rapidly progressive and debilitating inflammatory airway disorder associated with a very poor prognosis. This condition is almost exclusively found in Japan and is pathologically characterized by chronic recurrent bronchiolitis and peribronchiolitis with infiltration of the small airways. This can eventually lead to complete occlusion of the lumen of the respiratory bronchioles through the formation of lymph follicles, granulomas, and scar tissue. Clinically, pulmonary complaints such as dyspnea and productive cough are almost always accompanied by features of chronic rhinosi-

\section{KARGER}

Fax +4161306 1234 E-Mail karger@karger.ch www.karger.com

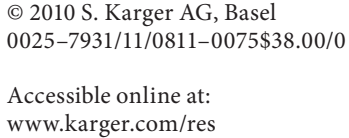

Drs. J. Altenburg, MD

Department of Pulmonary Diseases

Medical Centre Alkmaar, Wilhelminalaan 12

NL-1812 JD Alkmaar (The Netherlands)

Tel. +31 72548 2750, Fax +31 72548 2167, E-Mail j.altenburg@mca.nl 
nusitis $[2,3]$. High numbers of neutrophils and lymphocytes, together with high levels of IL- 8 and other proinflammatory cytokines and chemokines, are found in the bronchoalveolar lavage (BAL) fluid of DPB patients $[4,5]$. This indicates a chronic inflammatory process which is further deteriorated by the presence of pathogenic microorganisms. In the early course of the disease, sputum cultures of DPB patients mainly yield Haemophilus influen$z a e$, which is in many cases replaced by Pseudomonas aeruginosa (PA) in a more advanced stage of DPB $[4,6]$.

In addition, there appears to be a genetic component contributing to the disease mechanism. In approximately $60 \%$ of DPB patients the human leukocyte antigen (HLA)-B54 haplotype is found; it is only present in $11 \%$ of the healthy Japanese population [7].

After the introduction of EM as standard therapy for DPB in 1987, an impressive increase in 10-year survival was reported, i.e. from $10-20 \%$ to over $90 \%$ [2, 8-10].

The unexpected success was attributed to a previously unknown anti-inflammatory effect in addition to the antimicrobial potency of EM. This theory is supported by more recent studies which demonstrated that serum levels of EM in DPB patients were well below minimal inhibitory concentrations for the detected pathogens [9]. Furthermore, Nakamura et al. [11] showed that the beneficial effect of macrolides on pulmonary function and general well-being is frequently found without a change in the number or type of bacterial isolates.

Macrolides have been demonstrated to reduce IL-8 and IL- $1 \beta$ levels in the BAL fluid of DPB patients [12]. By influencing the production of these and other cytokines, they have a dampening effect on the proinflammatory response. Furthermore, the majority of cells involved in both the innate and adaptive immune response are, in one way or another, influenced when macrolide antibiotics are administered. Their antibacterial effect consists of the inhibition of bacterial protein synthesis, impaired bacterial biofilm synthesis, and the attenuation of other bacterial virulence factors. The effect on biofilm formation is suggested to be especially important in DPB patients who are frequently colonized with biofilm-forming PA. Results of Japanese in vitro studies indicate that azithromycin and clarithromycin change the structure of bacterial biofilms via the inhibition of polysaccharide synthesis, a major biofilm component $[13,14]$. An insufficient biofilm allows for enhanced phagocytosis and clearance of bacteria by alveolar macrophages $[15,16]$.

The effectiveness of macrolide maintenance therapy in order to reduce disease activity, exacerbations, and the decline in lung function has been well proven in CF [17]. Since 2002, five large randomized trials including a total of 608 patients have been published in which the role of macrolide maintenance treatment in CF is addressed [1822]. These studies all used azithromycin in different dosages ( 250 or $500 \mathrm{mg}$ daily, 250 or $500 \mathrm{mg}$ three times a week, or $1,200 \mathrm{mg}$ once a week) with a mean duration of 200 days. All studies showed a significant increase in lung function [forced expiratory volume in $\left.1 \mathrm{~s}\left(\mathrm{FEV}_{1}\right)\right]$. Additional outcomes were a decrease in the frequency and duration of infectious exacerbations, improvement in physical condition, and body weight gain.

The most recent trial was performed by McCormack et al. [22]. In their double-blind randomized study including 208 patients, improvement in lung function, Creactive protein, days spent in hospital, admission rate, and nutritional status was demonstrated after 6 months of treatment with azithromycin. Daily- $(250 \mathrm{mg})$ and weekly- (1,200 mg) administered azithromycin showed similar outcomes although gastrointestinal adverse effects were more common with weekly therapy. Nowadays, macrolide maintenance therapy is considered common practice in the treatment of CF patients, especially those colonized with PA. Colonization with PA is associated with reduced survival and a faster decline in lung function in DPB and CF [4, 23, 24]. Saiman et al. [25] were the first to study the effect of azithromycin (250-500 mg 3 times weekly for 24 weeks vs. placebo) on pulmonary function in 260 children with CF and mild lung disease, uninfected by PA. Treatment with azithromycin did not result in improved pulmonary function in this relatively healthy patient group. On the other hand, a promising amelioration in secondary endpoints weight and frequency of infectious exacerbations was observed after treatment with azithromcyin.

The improvement of pulmonary function, the reduction in exacerbation frequency, and the improvement of quality of life (QOL) shown in the aforementioned trials are often attributed to an anti-inflammatory effect of macrolide treatment $[18,19,22]$. Macrolides have a direct antimicrobial effect, but also modulate many aspects of the immune response. This so-called 'immune-modulatory effect' is exclusively demonstrated for 14- and 15-membered ring macrolides (EM, clarithromycin, roxithromycin, and azithromycin, respectively) [26-30]. Their effect on both inflammation and bacterial colonization appears to make 14- and 15-membered ring macrolides exceptionally suited to contribute to the treatment of chronic inflammatory diseases like COPD and bronchiectasis, having both distortion of the inflammatory 
response and bacterial infection as key features [31-33]. An overview of the biological mechanisms through which macrolides exert their immunomodulatory effect is provided in part 1 of this series of articles [34].

Considering the increasing popularity of macrolide maintenance therapy, concern regarding possible disadvantages seems appropriate. In the past, macrolides, especially EM, were known for their ability to cause cardiac arrhythmias and hearing loss when administered in high dosages $[35,36]$. Finding out whether this also applies to long-term, low-dose macrolide therapy is relevant to clinical practice. In addition, a reduced susceptibility or resistance to macrolides is very likely to develop when these drugs are administered in low dosages during longer periods of time.

We performed a literature search for studies exploring the clinical effectiveness of long-term macrolide therapy in COPD, chronic rhinosinusitis, non- $\mathrm{CF}$ bronchiectasis, and asthma. We focused primarily on including randomized controlled trials, if available.

An additional search was performed for studies about macrolide safety and the emergence of macrolide resistance during long-term macrolide therapy. As none were found, the search was broadened to macrolide safety and resistance in general, with special attention to ototoxicity and cardiac toxicity.

\section{Non-CF Bronchiectasis and Long-Term, Low-Dose Macrolide Treatment}

In bronchiectasis, irreversible, pathologic dilatation of the small and medium-sized bronchi results from an ongoing cycle of chronic inflammation and bacterial colonization (vicious circle theory) $[31,37,38]$. Although the etiology remains unclear in a large percentage of patients (53-60\%), common causes include immune defects, early childhood infections, and aspiration [39-41]. Clinically, this results in chronic and sometimes debilitating symptoms such as productive cough, dyspnea, and recurrent infections. As early as 1965, maintenance therapy with macrolide antibiotics (e.g. oleandomycin) was investigated as a potential remedy for chronic symptoms in patients with hypogammaglobulinemia and bronchiectasis [42].

Three small, randomized controlled trials investigating the efficacy of macrolide antibiotics in non-CF bronchiectasis were published in the last decade. Patient numbers did not exceed 35 and all trials used different macrolide products administered for relatively short periods of time. A total of 59 children and 21 adults with proven bronchiectasis were treated with roxithromycin $(4 \mathrm{mg} / \mathrm{kg}$ b.i.d. for 12 weeks), EM ( $500 \mathrm{mg}$ b.i.d. for 8 weeks), or clarithromycin ( $15 \mathrm{mg} / \mathrm{kg}$ daily for 12 weeks). Improved sputum properties, a decrease in markers of airway inflammation, reduced sputum volume, and decreased bronchial reactivity as measured by methacholine challenge were demonstrated in patients receiving macrolide treatment as compared to controls [43-45]. Only 1 randomized trial demonstrated a small but significant improvement in $\mathrm{FEV}_{1}$ and forced vital capacity (FVC) [44]. A small openlabel crossover study enrolling 12 patients investigated the effect of azithromycin (500 mg 2 times a week) added to standard treatment during 6 months [46]. Despite the small numbers, this study showed significantly fewer infectious exacerbations and reduced sputum volume. No change in lung function measurements was found. A fairly recently performed patient-control study showed comparable results concerning exacerbation frequency. Longterm azithromycin treatment $(250 \mathrm{mg} 3$ times a week for 4-38 months) of 39 patients with bronchiectasis and frequent exacerbations ( $>4$ in the past 12 months) resulted in a significant reduction in infectious exacerbations. Furthermore, these patients reported a significant improvement of symptoms. An improvement in all lung function parameters was reported, but only the improvement in carbon monoxide transfer factor (TLCO) reached statistical significance. The severity of the symptoms in this group of patients made the researchers abstain from a placebo-controlled study design [47].

In conclusion, data from numerous, but mainly small, studies suggest that long-term macrolide treatment in patients with non-CF bronchiectasis could have a positive influence on the frequency of infections, sputum volume, and inflammation. The effect of macrolide maintenance therapy on lung function remains uncertain. In turn, improvement of these parameters has a potentially large effect on QOL in this group of patients.

\section{COPD and Long-Term, Low-Dose Macrolide Treatment}

Most research on the role of macrolide antibiotics in COPD focuses on short-course treatment in acute exacerbations. Current guidelines promote the administration of a short course of antibiotics for patients with an AECOPD and an increase in sputum purulence or signs of pneumonia [48]. A meta-analysis of macrolide antibiotics versus quinolones and macrolides versus amoxicil- 
line/clavulanate in patients with acute bacterial exacerbations of chronic bronchitis showed no difference in treatment success [49].

Based on the most recent Cochrane review, long-term, prophylactic antibiotic therapy in stable COPD was not recommended [50]. The reviewers, however, mainly included trials conducted over 30 years ago, when antibiotic susceptibility and availability may have been different. Moreover, they did not distinguish between macrolides and other groups of antibiotics.

Recently, 2 randomized trials have investigated the efficacy of long-term macrolide treatment in COPD. Banerjee et al. [51] investigated 67 patients in a prospective, double-blind, randomized, placebo-controlled study using clarithromycin $500 \mathrm{mg}$ for 3 months. Although a large number of different parameters were measured (health status, quantitative sputum cultures, exacerbation rate, spirometry, C-reactive protein, and the shuttle walk test), no significant change was seen in any of them. The authors state that this may be due to the small number of patients included in the study and to the relatively short treatment time. The results of another very recent study seem to support their statement. Seemungal et al. [33] established a positive effect of prophylactic macrolide treatment in moderate-to-severe COPD in their study with a longer treatment time and longer follow-up. In this single-center, randomized, double-blind, placebo-controlled trial they treated 109 patients with EM $250 \mathrm{mg}$ b.i.d or placebo for 1 year. Their most important finding was a 35\% reduction of exacerbations in the macrolide arm of the study compared to the placebo arm, with a tendency towards shorter and less severe exacerbations in the macrolide arm. No significant change was found in lung function parameters, sputum and airway inflammatory markers, side effects, and bacteria isolated.

Contemplating these results and the evidence of the anti-inflammatory and antibacterial effect of macrolide antibiotics, one could argue that low-dose macrolides, when applied over a long enough period, may have beneficial effects in moderate-to-severe COPD.

Currently, a large multicenter study is being performed investigating the effect of chronic macrolide administration on the frequency and severity of COPD exacerbations. 1,130 patients receive azithromycin ( $250 \mathrm{mg}$ once daily) or placebo in a randomized, double-blind fashion [52, 53]. The results of this study will presumably provide more insight into the role of macrolide prophylaxis in COPD.

\section{Long-Term, Low-Dose Macrolides in Chronic Rhinosinusitis}

Chronic rhinosinusitis is characterized by hyperplasia, hypertrophy, and hypersecretion of the nasal and paranasal sinus mucosae. Typically, high levels of neutrophils and proinflammatory cytokines, especially IL-8, are found in nasal secretions. In ear, nose, and throat medicine there appears to exist a moderate recommendation for the use of long-term macrolide treatment in chronic sinusitis [54]. This recommendation, however, is based on limited data. Most studies that focus on long-term macrolide treatment in chronic sinusitis are small, open-label series. Consistent findings across these studies are: an improvement in sinusitis symptoms, shrinkage in the size of nasal polyps, and a decrease in the levels of proinflammatory cytokines in nasal secretion [55-59]. In 2006, the first double-blind, randomized, controlled trial (roxithromycin $150 \mathrm{mg}$ o.d. or placebo for 3 months) was published [60]. The macrolide-treated group $(n=29)$ showed a significant improvement in symptom scores, endoscopy findings, and olfactory function. Nasal lavage assays showed decreased levels of IL-8 in the roxithromycintreated group. Significant improvements started to occur after 6 weeks of treatment. These findings are consistent with previous open-label studies which showed that a prolonged course of macrolide therapy of at least 12 weeks is required in order to reach and maintain maximal clinical benefit $[55,61]$. A subgroup analysis showed that the improvement of symptoms was most distinct in patients with low levels of IgE. This phenomenon was also observed in an earlier Japanese open-label study. Of the 16 patients receiving macrolide maintenance therapy, the ones with low levels of IgE (below $250 \mathrm{U} / \mathrm{ml}$ ) showed a significantly higher rate of symptomatic improvement [62]. These findings suggest that long-term macrolide treatment could be beneficial in chronic rhinosinusitis, but treatment periods longer than 12 weeks are necessary to maintain the beneficial effect. Furthermore, a subgroup of patients with low levels of serum IgE can be identified which seems to benefit the most from macrolide treatment.

\section{Long-Term, Low-Dose Macrolides in Asthma}

Bronchial hyperresponsiveness in asthma is related to airway inflammation. Asthma is considered a chronic inflammatory disease of the airways which in most cases requires long-term anti-inflammatory therapy [32, 63]. Chronic inflammation in asthma is characterized by in- 
creased numbers of activated lymphocytes, eosinophils, and variably reported increases in mast cells. The walls of the conducting airways are thickened and the lumen is obscured with an infiltrate of inflammatory cells and excess mucus [64]. Published reports have demonstrated an anti-inflammatory effect of macrolide antibiotics in asthma. This class of antibiotics has been found to reduce airway hyperresponsiveness, NO production, cytokine expression, and eosinophilic infiltration [65-70]. Another mechanism of action is proposed by Takizawa et al. [71]; they demonstrated an attenuation of endothelin-1 (a potent bronchoconstrictive peptide) expression by bronchial epithelial cells after in vitro treatment with EM and clarithromycin.

Two methods for the long-term application of macrolide antibiotics in asthma have been specifically studied.

\section{Addition of Troleandomycin to Steroid Treatment}

Troleandomycin (TAO), a 14-membered ring macrolide, was first described as a treatment for steroiddependent asthma in 1974 [72]. Besides its antibacterial properties, anti-inflammatory effects of TAO have been reported. However, its most important mechanism of action in steroid-dependent asthma patients appears to be the increase in the bioavailability of steroids. Use of TAO slows the elimination of methylprednisolone, effectively doubling the half-life, due to reduced liver metabolism [72-74]. Initial research in small groups of patients showed promising results. Sixteen severe corticosteroiddependent yet resistant outpatient asthmatics were well controlled after 4 months of the addition of TAO with minimal side effects [76]. Wald et al. [77] introduced another protocol with a lower starting dose of TAO and rapid steroid tapering. Side effects were even less present and a marked increase in pulmonary function parameters was observed. Nevertheless, as time went on, increasing concern arose regarding the rise in corticosteroid induced side effects in patients receiving TAO and steroids [78].

Since 1990, three randomized trials investigating the use of TAO in patients with corticosteroid-dependent asthma have been published [79-81]. Two of these trials reported more steroid-related side effects in patients who were treated with TAO in addition to corticosteroids [80, 81]. A meta-analysis of 108 patients ( 75 adults and 33 children) of these 3 studies failed to show a significant reduction in the required dose of oral steroids in patients treated with TAO. Furthermore, there was no improvement in lung function when pooled data from 2 of these studies were analyzed [82].

Immunomodulatory Effects of Macrolide Antibiotics - Part 2
A steroid-sparing effect of clarithromycin was demonstrated in a small study in 3 steroid-dependent asthma patients by Garey et al. [83]. They noticed a significant decrease in prednisone requirements in all 3 patients and there was a discontinuation of prednisone treatment in 2 patients due to clarithromycin treatment.

\section{Treatment of Bacterial Infection}

Mycoplasma pneumoniae (MP) or Chlamydophila pneumoniae (CP) may be involved in the pathogenesis of asthma [84]. In 2001, the first systematic evaluation of $\mathrm{CP}$ and MP infections in 55 patients with stable asthma showed the presence of either MP or CP as detected by PCR in $56.4 \%$ of patients compared to $9 \%$ in healthy control subjects $(\mathrm{p}<0.02)$ [85]. The authors concluded that a significant number of patients with stable asthma are infected by 1 of these microorganisms. Furthermore, a substantial number of acute exacerbations (18-21\%) in asthma are caused by MP [86-88]. The presence of such microorganisms predisposes patients to more severe asthma and more frequent and serious exacerbations [89-91]. Certain features of asthma, such as bronchial hyperreactivity and impaired pulmonary function, have been proven to persist long after chlamydial or mycoplasmal infections $[92,93]$.

These findings formed the starting point of the randomized trials that investigated the role of macrolide treatment in subjects with serological evidence of infection with either MP or CP.

Kraft et al. [94] treated 55 asthma patients with either clarithromycin (500 mg b.i.d) or placebo. When subjects who received clarithromycin were divided by PCR status, only patients with positive PCR findings for $\mathrm{CP}$ or MP showed a significant increase in $\mathrm{FEV}_{1}$ and a reduced expression of IL-5 (a proinflammatory cytokine). No improvement in any parameter was seen in PCR-negative clarithromycin-treated patients. In a large multicenter trial, 232 subjects with asthma and high titers of IgA and/or IgG antibodies to $\mathrm{CP}$ were randomized to roxithromycin $150 \mathrm{mg}$ b.i.d. or placebo for 6 weeks [95]. Treatment with roxithromycin lead to minimal improvement in asthma control (slight improvement in morning peak expiratory flow). Due to this small effect, the calculated sample size was found to be insufficient to gain adequate power. They found no change in symptom scores, and the improvement in peak flow measurement disappeared after treatment was discontinued. Hahn et al. [96] completed a community-based pilot study in which 45 patients with mildto-moderate asthma were randomized to azithromycin (600 mg weekly) or placebo for 6 weeks in addition to their 
usual asthma treatment. Not only did they find a clear correlation between asthma severity and serum IgA antibodies against $\mathrm{CP}$, but they also demonstrated a beneficial effect of azithromycin on overall asthma symptoms. Due to its pilot nature and the small number of participants, no significant conclusions could be drawn.

Although there is convincing evidence of a role of MP and $\mathrm{CP}$ in the pathogenesis of asthma, results of randomized trials investigating the effect of macrolide therapy in asthmatic patients with serologic evidence of atypical infection are, to date, unsatisfactory. Perhaps advanced techniques using qPCR will elucidate the role of bacterial burdens and the potential benefit of long-term macrolide treatment in asthmatic patients with significant bacterial burdens.

The use of macrolide maintenance therapy in asthma in general was the subject of a Cochrane review in 2005 [97]. After long-term macrolide treatment no significant change in lung function and only a small reduction in symptoms were found, although serum markers of eosinophilic inflammation were found to be markedly decreased.

The authors concluded that: 'Even though some clinical data indicate a positive effect of macrolides in asthmatic patients in the absence of relevant side effects, these data are insufficient to recommend routine use of macrolides for the control of asthma at present.'

Randomized controlled trials performed after 2005 focus on the possible immune-modulating effect of macrolides in asthma. A small Italian study investigated the effect of 8 weeks of azithromycin treatment versus placebo in 16 asthmatic children [98]. Although they found a significant decrease in inflammatory markers in the azithromycin-treated group, no change in lung function was observed. Simpson et al. [99] distinguished 2 types of asthmatic patients: those with allergic asthma, characterized by eosinophilic inflammation and high IgE titers, and those with noneosinophilic asthma (NEA) which features increased neutrophil numbers and high IL-8 levels in the airways. Forty-six patients with refractory asthma, randomized to clarithromycin (500 mg b.i.d.) or placebo, were stratified according to neutrophil proportion and treated for 8 weeks. The authors demonstrated a significant reduction in IL-8 and neutrophil numbers and an improvement in QOL in all patients after 8 weeks of clarithromycin treatment. In view of the fact that they found a nonsignificant drop in all other inflammation markers, the authors suggest that clarithromycin causes an overall downregulation of neutrophil activation and mediator release. The anti-inflammatory effect was most marked in NEA patients (with high neutrophil proportions), suggesting that long-term macrolide therapy could prove to be a good add-on therapy in refractory NEA. So, in line with the previously mentioned studies on chronic rhinosinusitis, it is plausible that a subgroup of patients with high IL-8 and low IgE levels benefits most from long-term macrolide treatment.

\section{Long-Term Macrolide Therapy in Cryptogenic Organizing Pneumonia}

Organizing pneumonia is a nonspecific inflammatory disorder pathologically characterized by the presence of granulation tissue and fibrosis in the alveoli and distal bronchioles [100]. In the presence of specific clinicoradiological features, this entity is defined as cryptogenic organizing pneumonia (COP).

In 1993, Japanese researchers demonstrated that some patients with COP show clinical and radiological improvement after prolonged treatment with EM [101].

A more recent report on clarithromycin treatment in 3 patients with COP describes a complete resolution of pulmonary and systemic symptoms in 2 of these patients while being treated with low dosages $(250 \mathrm{mg}$ once or twice daily) for 3 months [102]. A possible mechanism of action is proposed by Hotta [103] who demonstrated a significant decrease in IL-8 levels and neutrophil numbers in the BAL fluid of 8 patients with COP after treatment with EM (600 mg daily for 3 months), indicating that macrolides cause an inhibition of neutrophil accumulation in the peripheral airways in patients with COP. No large-scale studies, however, are available to confirm these findings. To date, corticosteroids are advised as the first choice of treatment for COP.

\section{Safety of Long-Term Macrolide Treatment}

Gastrointestinal complaints are the most common adverse effects in patients receiving macrolide therapy. Gastrointestinal adverse effect rates of 15-20\% for EM, 8.7\% for clarithromycin, and $9.6 \%$ for azithromycin have been observed in patients receiving short courses of macrolides [104]. In randomized trials of long-term, low-dose macrolide treatment in chronic pulmonary diseases, mild-to-moderate gastrointestinal complaints have been reported which hardly ever cause study drug discontinuation (table 1). 
Table 1. Adverse events reported in randomized trials of long-term macrolide treatment in chronic sinopulmonary diseases

\begin{tabular}{|c|c|c|c|c|}
\hline First author & Patient group & $\begin{array}{l}\text { No. of } \\
\text { patients }\end{array}$ & Intervention & Adverse events by treatment group \\
\hline Wolter, $2002[21]$ & $\mathrm{CF}$, adults & 60 & azithromycin $250 \mathrm{mg} /$ day; 3 months & urticaria (1), neutropenia (1), and rash (1) \\
\hline Equi, 2002 [19] & $\mathrm{CF}$, children & 41 & azithromycin 250 or $500 \mathrm{mg} /$ day; 6 months & transient elevation of liver enzymes (1) \\
\hline Clement, 2006 [18] & CF, children & 82 & $\begin{array}{l}\text { azithromycin } 250 \text { or } 500 \mathrm{mg}, 3 \text { times a week; } \\
12 \text { months }\end{array}$ & $\begin{array}{l}\text { gastrointestinal side effects (16), ENT infections (14), } \\
\text { and headache (2) }\end{array}$ \\
\hline $\begin{array}{l}\text { McCormack, } \\
2007[22]\end{array}$ & $\begin{array}{l}\text { CF, adults + } \\
\text { children }\end{array}$ & 208 & $\begin{array}{l}\text { azithromycin } 250 \mathrm{mg} / \text { day vs. azithromycin } \\
1,200 \mathrm{mg} / \text { week; } 6 \text { months }\end{array}$ & $\begin{array}{l}>4 \text {-fold increase in liver enzymes ( } 8 \text { ) and } \\
\text { gastrointestinal side effects ( } 36)\end{array}$ \\
\hline Steinkamp, 2008 [82] & $\begin{array}{l}\text { CF, adults + } \\
\text { children }\end{array}$ & 38 & $\begin{array}{l}\text { azithromycin 500/750/1,000/1,250 mg/week; } \\
8 \text { weeks }\end{array}$ & gastrointestinal side effects and rash \\
\hline Black, 2001 [95] & Asthma, adults & 232 & roxithromycin $150 \mathrm{mg}$ b.i.d.; 6 weeks & $\begin{array}{l}\text { gastrointestinal side effects (19) and transient } \\
\text { elevation of liver enzymes (6) }\end{array}$ \\
\hline Kostadima, 2004 [83] & Asthma, adults & 63 & clarithromycin 250 mg b.i.d./t.i.d.; 8 weeks & withdrawal due to gastrointestinal side effects (1) \\
\hline Hahn, 2006 [96] & Asthma, adults & 45 & azithromycin $600 \mathrm{mg} /$ week; 3 months & mild-to-moderate gastrointestinal side effects (5) \\
\hline Wallwork, $2006[60]$ & $\begin{array}{l}\text { Chronic sinusitis, } \\
\text { adults }\end{array}$ & 64 & roxithromycin $150 \mathrm{mg} / \mathrm{day} ; 3$ months & withdrawal due to gastrointestinal side effects (1) \\
\hline Banerjee, 2008 [51] & COPD, adults & 46 & clarithromycin $500 \mathrm{mg} /$ day; 3 months & withdrawal due to gastrointestinal side effects (1) \\
\hline Seemungal, 2008 [33] & COPD, adults & 109 & erythromycin $250 \mathrm{mg}$ b.i.d.; 12 months & $\begin{array}{l}\text { gastrointestinal side effects (8), rash (3), and tinnitus } \\
(1)^{\mathrm{a}}\end{array}$ \\
\hline
\end{tabular}

Numbers in parentheses represent number of patients. ENT = Ear, nose and throat. ${ }^{\text {a }}$ There was no significant difference between the study drug and placebo.

Other infrequently reported side effects related to macrolide use are rash $(0.5-6 \%)$ and hepatotoxicity (most frequently a transient increase in liver enzymes or cholestasis) $[104,105]$. As with all macrolide-related side effects, these are more common following treatment with EM than with the other 14-and 15-membered ring macrolides $[104,106]$. Furthermore, the incidence of adverse effects increases when macrolides are administered in larger dosages or reaching higher serum levels [22, 104, 107].

Ototoxicity and cardiac toxicity are familiar, though very rare, side effects of macrolide antibiotics. Because of their infrequent occurrence, these side effects are hardly ever observed in clinical trials. Few of the aforementioned trials monitored for cardiac arrhythmia or hearing loss, so no solid data are available concerning the incidence of these side effects during the long-term use of macrolides. The incidence and outcome of these conditions during the short-term use of macrolides has, however, been established. Furthermore, the potential seriousness of these 2 side effects merits their being discussed in detail.

\section{Ototoxicity}

Ototoxicity caused by macrolide use is typically described as reversible, sensorineural, bilateral, hearing loss involving the lower or speech frequencies. Most articles on this subject are case reports or review articles mainly published more than 15 years ago [104, 108-110]. Swanson et al. [110] conducted the only prospective case-control study to date in which hearing tests were carried out in 45 patients receiving intravenous antibiotic treatment for pneumonia. Twenty-one percent of patients who were treated with high dosages of EM developed varying degrees of hearing impairment as opposed to none of the patients who were treated with another antimicrobial agent. Furthermore, they demonstrated that only renal impairment or decreased total systemic clearance was associated with the development of hearing loss in this small group of patients.

This study and other reports point out that macrolide use causes ototoxicity in an obviously dose-dependent fashion. Only daily macrolide dosages similar to azithromycin $1,500 \mathrm{mg}$ or clarithomycin 2,000 $\mathrm{mg}$ changed the 
Table 2. Risk factors for QT prolongation or TdP during use of macrolide antibiotics

Age $>80$ years

Female gender

Heart disease

Use of other QT prolonging medication

Reduced drug elimination

Hypokalemia/hypomagnesemia

Prolonged QT interval before therapy

Bradycardia

Genetic predisposition

cochlear response rate in guinea pigs [111]. Case reports about EM ototoxicity describe hearing impairment mainly in association with intravenous therapy and/or dosages $>4,000$ mg o.d. $[105,108,109,112]$.

Ototoxicity following the long-term administration of macrolide antibiotics has been described in the treatment of Mycobacterium avium complex (MAC) infections. In a prospective, nonblinded study, $25 \%$ of patients receiving high dosages of azithromycin (600 mg daily) complained of hearing impairment. This was confirmed by audiometry in 6 out of 10 patients. After decreasing the dosage of azithromycin to $300 \mathrm{mg}$ /day or less, ototoxicity was no longer noticed; this was confirmed by audiological testing in 3 of these patients [107]. Wallace et al. [36] also reported reversible hearing loss in their series of patients with AIDS and disseminated M. avium disease. Fourteen out of 21 patients who were treated with daily dosages of $500 \mathrm{mg}$ azithromycin as part of a 3-drug combination regimen between 1992 and 1993 spontaneously complained of hearing loss. No more hearing loss occurred after replacement of azithromycin with clarithromycin in their standard treatment regimen. A few years later, Tseng et al. [113] reported reversible ototoxicity in $17 \%$ of $46 \mathrm{HIV}$ patients treated with azithromycin $600 \mathrm{mg}$ daily.

No solid information is available concerning the incidence of ototoxicity during long-term macrolide use in lower dosages.

In conclusion, macrolide antibiotics are able to cause hearing loss that is almost always reversible, and apparently this occurs only when it is administered in high dosages. The incidence of ototoxicity during low-dose, longterm macrolide use is unknown but, considering the above, probably negligible.

\section{Cardiac Toxicity}

In case reports, macrolide antibiotics have been associated with a prolongation of the QT interval and torsades de pointes (TdP). The European Society of cardiology considers EM and clarithromycin to be drugs that are particularly associated with cardiac arrhythmias [114]. Intravenous use of EM has been associated with a particularly high risk of arrhythmias, probably due to the poorer absorption of oral preparations $[114,115]$. One large cohort study in 2004 found a 2-fold increased risk of sudden death from cardiac causes among patients currently using EM compared to those who had not used any of the antibiotic medications studied [35]. TdP is a polymorphic ventricular tachycardia, usually preceded by a prolongation of the QT interval, caused by altered cardiac repolarization. It may be asymptomatic but has also been associated with syncope and sudden death. Drug-induced prolongation of the QT interval is generally regarded as a reliable predictive measure for the risk of TdP arrhythmias.

Macrolides have 2 potential effects on the QT interval: (1) intrinsic prolongation, i.e. macrolide antibiotics prolonging the repolarization period of the action potential by blocking the HERG potassium channels [116] and (2) inhibition of the metabolism of other proarrhythmogenic drugs by acting on cytochrome $\mathrm{P} 450$ in the liver. When, for instance, EM and other inhibitors of cytochrome P450 were concurrently prescribed, a 5-fold greater risk of cardiac sudden death was reported [35]. Patient characteristics associated with a greater risk of developing cardiac arrhythmias following macrolide use are shown in table $2[115,117,118]$.

Information about the incidence of (fatal) cardiac arrhythmias associated with macrolide use most often comes from cohort studies and adverse event reporting systems. The only randomized clinical trial of long-term macrolide treatment including follow-up ECGs reported no arrhythmias [51].

Retrospective evaluation of reports regarding $\mathrm{TdP}$ or ventricular tachycardia related to macrolides (EM, clarithromycin, and azithromycin) in the US Food and Drug Administration Adverse Event Reporting System (FDAAERS) yielded 156 reports in a 13-year period (1987-2000). In half of these cases $(n=78)$, a macrolide with no concomitant use of other QT-prolonging drugs was involved. Fatal outcomes were mentioned in $12 \%(\mathrm{n}=9)$ of the macrolide-only reports. Limitations of this analysis put forth by the authors were the well-known biases of spontaneous reports and the fact that TdP was not electrocardiographically confirmed in all cases [118]. The incidence of sponta- 
neous reports of TdP marked out against the number of macrolide prescriptions from 1993 to 2000 is 0.06 (azithromycin) - 0.18 (clarithromycin) per million prescriptions, according to FDA databases (http://www.fda.gov/ohrms/ dockets/ac/01/slides/3746s_02_shaffer_rev/sld020.htm).

The aforementioned data indicate that, although cardiac toxicity is rare, special care must be taken when administering macrolide antibiotics, especially EM IV, to certain groups of patients. In female patients older than 80 years with cardiac comorbidity or using other proarrhythmogenic drugs, ECG follow-up to observe possible QT prolongation during the use of macrolide antibiotics should be considered.

\section{Macrolide Resistance}

\section{Epidemiology}

Reduced susceptibility to antibiotics of respiratory pathogens can be considered an increasing global problem. In general, macrolide resistance has increased considerably over the last decade [119-122]. Both macrolide resistance rates and resistance mechanisms, however, vary considerably depending on the location. The highest incidence of macrolide resistance in Streptococcus pneumoniae is found in Japan, where $80-100 \%$ of pneumococci have been found to be macrolide resistant $[119,123]$. In contrast, resistance rates in Scandinavia (Norway and Sweden) are remarkably low, i.e. about 8-9\% [124]. A significant association between prescription of macrolides and local resistance has been observed in most studies [121, 124-127].

Together with an increase in macrolide resistance in respiratory pathogens, a parallel increase in the oropharyngeal carriage of macrolide-resistant commensals has been observed. High percentages of macrolide resistance of up to $94 \%$ among viridans group streptococci have been reported in healthy volunteers worldwide [128, 129]. Although these commensals usually do not cause infections in healthy persons, they may be considered a threat for 2 reasons: they could cause infection in immunecompromised hosts, and they might transfer the resistance determinants to pathogenic streptococci $[129,130]$.

\section{Development of Macrolide Resistance during Long-Term Macrolide Therapy}

In long-term use of antibiotics, the reduced susceptibility of potentially pathogenic microorganisms poses a threat. Nevertheless, only a few of the randomized clin- ical trials mentioned in this review address this problem. The ones that did monitor for resistance found no macrolide-resistant organisms during follow-up after 3 months of macrolide maintenance therapy in COPD ( $\mathrm{n}=$ 46) and chronic rhinosinusitis $(\mathrm{n}=64)$ patients $[51,60]$. A recently performed trial of EM in COPD $(n=109)$ patients found no influence on the microbiological profile of sputum from the use of EM. Only 1 case of EM resistance occurred in the macrolide arm of the study after 12 months [33].

In the field of CF research, where long-term macrolide therapy is often practiced, the problem of the reduced susceptibility of microorganisms following this treatment has been covered more thoroughly, though retrospectively [131]. Phaff et al. [132] investigated the macrolide resistance of Staphylococcus aureus and H. influenzae in the sputum isolates of $156 \mathrm{CF}$ patients receiving azithromycin maintenance therapy with a mean duration of 397 days. EM resistance in S. aureus increased from $6.9 \%$ at the commencement of study to $53.8 \%$ after 5 years of follow-up. Concomitantly, a 10 -fold increase in clarithromycin resistance in $H$. influenzae isolates (3.7$37.0 \%)$ was observed. Other notable results came from a retrospective study by Tramper-Stranders et al. [133]. They noticed macrolide resistance in all (100\%) S. aureus isolates obtained from $100 \mathrm{CF}$ patients after azithromycin treatment with a mean duration of 3.5 years. The emergence of macrolide-resistant $S$. aureus was not related to pulmonary function decline. Similar numbers were published concerning the emergence of macrolide-resistant Staphylococcus pneumoniae following macrolide treatment. After 4 years of EM or clarithromycin maintenance treatment, $98.2 \%$ of pneumococcal isolates recovered from 57 CF patients showed macrolide resistance [134].

Based on these results, we conclude that macrolide resistance in respiratory pathogens only significantly increases when maintenance therapy is given for a long period of time (3-5 years). Ultimately, resistance rates can become very high, i.e. up to $100 \%$. A maintenance regimen that involves the seasonal administration of macrolides (during the autumn and winter periods), as has already been used in some Dutch hospitals, might attenuate the emergence of resistance. Investigating the effect of such a regimen in a randomized trial might be helpful.

The impact of macrolide resistance on the clinical outcome is almost exclusively described in observational studies in patients with community-acquired pneumonia, the results of which are subject to dual interpretation. Although considerable numbers of macrolide-resistant organisms were found, no significantly increased mor- 
bidity and mortality was demonstrated in these patients [135-137]. Other authors, however, believe that the observational study results indicate that macrolide insusceptibility is responsible for treatment failure in these patients and may be considered a serious hazard $[120,130,138$ 140].

\section{Macrolide Resistance in Patients Treated for MAC Diseases}

Long-term macrolide therapy plays a key role in treatment regimens and prophylaxis for MAC and other atypical mycobacteria. According to the guidelines of the American Thoracic Society published in 2007, the standard treatment regimen of MAC pulmonary disease in HIV-negative patients should contain either clarithromycin (500-1,000 mg thrice weekly) or azithromycin (250$600 \mathrm{mg}$ thrice weekly). The dosages depend on the status and/or severity of the disease [141].

Macrolide resistance is much more common in patients receiving macrolide monotherapy or macrolide plus a quinolone for more than 1 month during their treatment period. Griffith et al. [142] reported the occurrence of macrolide-resistant pathogens in $20 \%$ of patients who were initially treated with macrolide monotherapy for MAC lung disease. Conversely, only $4-6.6 \%$ of patients with MAC lung disease became resistant when a 3 -dose regimen, including ethambutol and rifampin or rifabutin, was used from the start of treatment $[143,144]$.

Macrolide resistance in MAC pulmonary disease appears to be associated with higher relapse rates and a poor prognosis. In a retrospective study in 51 patients with MAC lung disease, 1-year mortality increased from 0 to
$34 \%$ when patients remained culture-positive despite adequate treatment [142]. A randomized study by Benson et al. [145] in patients with disseminated MAC showed a spectacular decrease in relapse rates when a 3-drug regimen was used (6\%) compared to macrolide monotherapy (24\%).

To avoid the emergence of resistant organisms, it is recommended that MAC lung disease be treated with a macrolide in combination with 2 or 3 other medications $[141,146,147]$.

\section{Conclusion}

In pulmonary practice, long-term macrolide maintenance therapy has become increasingly popular for the treatment of patients with other chronic inflammatory conditions, such as COPD, asthma, bronchiectasis, and sinusitis, who have recurrent infections or other signs of 'badly regulated disease'. Scientific evidence to justify this, however, is still conflicting in the case of COPD and lacking in non-CF bronchiectasis, sinusitis, and asthma. Study results to date show a beneficial effect of macrolides on exacerbation frequency, sputum volume, and inflammatory markers. Low-dose macrolides should be applied for at least 3 months to establish and maintain these advantageous effects. Gastrointestinal complaints are the most frequently reported adverse effects of long-term macrolide treatment.

Increased macrolide resistance among different pathogens has been documented in maintenance treatment, but the clinical significance of this reduced susceptibility to macrolides remains unknown.

\section{References}

1 Kudoh S, Uetake T, Hagiwara K: Clinical effects of low-dose long-term erythromycin chemotherapy on diffuse panbronchiolitis (in Japanese). Nihon Kyobu Shikkan Gakkai Zasshi 1987;25:632-642.

2 Kudoh S, Azuma A, Yamamoto M: Improvement of survival in patients with diffuse panbronchiolitis treated with low-dose erythromycin. Am J Respir Crit Care Med 1998;157: 1829-1832.

-3 Martinez FJ, Simon RH: Clinical implications of macrolide therapy in chronic sinopulmonary diseases. Curr Pharm Des 2004; 10:3095-3110.
Poletti V, Casoni G, Chilosi M: Diffuse panbronchiolitis. Eur Respir J 2006;28:862-871.

5 Sakito O, Kadota J, Kohno S: Interleukin 1 beta, tumor necrosis factor alpha, and interleukin 8 in bronchoalveolar lavage fluid of patients with diffuse panbronchiolitis: a potential mechanism of macrolide therapy. Respiration 1996;63:42-48.

6 Homma H, Yamanaka A, Tanimoto S: Diffuse panbronchiolitis: a disease of the transitional zone of the lung. Chest 1983;83:63-69.

7 Sugiyama Y, Kudoh S, Maeda H: Analysis of HLA antigens in patients with diffuse panbronchiolitis. Am Rev Respir Dis 1990;141: 1459-1462.
Fujii T, Kadota J, Kawakami K: Long term effect of erythromycin therapy in patients with chronic Pseudomonas aeruginosa infection. Thorax 1995;50:1246-1252.

$\checkmark 9$ Nagai H, Shishido H, Yoneda R: Long-term low-dose administration of erythromycin to patients with diffuse panbronchiolitis. Respiration 1991;58:145-149.

10 Tateda K, Ishii Y, Kimura S: Suppression of Pseudomonas aeruginosa quorum-sensing systems by macrolides: a promising strategy or an oriental mystery? J Infect Chemother 2007;13:357-367. 
-11 Nakamura H, Fujishima S, Inoue T: Clinical and immunoregulatory effects of roxithromycin therapy for chronic respiratory tract infection. Eur Respir J 1999;13:1371-1379.

-12 Hiratsuka T, Mukae H, Iiboshi H: Increased concentrations of human beta-defensins in plasma and bronchoalveolar lavage fluid of patients with diffuse panbronchiolitis. Tho$\operatorname{rax} 2003 ; 58: 425-430$.

- 13 Ichimiya T, Takeoka K, Hiramatsu K: The influence of azithromycin on the biofilm formation of Pseudomonas aeruginosa in vitro. Chemotherapy 1996;42:186-191.

14 Kondoh K, Hashiba M, Baba S: Inhibitory activity of clarithromycin on biofilm synthesis with Pseudomonas aeruginosa. Acta Otolaryngol Suppl 1996;525:56-60.

-15 Ichimiya T, Yamasaki T, Nasu M: In-vitro effects of antimicrobial agents on Pseudomonas aeruginosa biofilm formation. J Antimicrob Chemother 1994;34:331-341.

16 Takeoka K, Ichimiya T, Yamasaki T: The in vitro effect of macrolides on the interaction of human polymorphonuclear leukocytes with Pseudomonas aeruginosa in biofilm. Chemotherapy 1998;44:190-197.

17 Bilton D: Update on non-cystic fibrosis bronchiectasis. Curr Opin Pulm Med 2008; 14:595-599.

18 Clement A, Tamalet A, Leroux E: Long term effects of azithromycin in patients with cystic fibrosis: a double blind, placebo controlled trial. Thorax 2006;61:895-902.

-19 Equi A, Balfour-Lynn IM, Bush A: Long term azithromycin in children with cystic fibrosis: a randomised, placebo-controlled crossover trial. Lancet 2002;360:978-984.

-20 Saiman L, Marshall BC, Mayer-Hamblett N: Azithromycin in patients with cystic fibrosis chronically infected with Pseudomonas aeruginosa: a randomized controlled trial. JAMA 2003;290:1749-1756.

-21 Wolter J, Seeney S, Bell S: Effect of long term treatment with azithromycin on disease parameters in cystic fibrosis: a randomised trial. Thorax 2002;57:212-216.

22 McCormack J, Bell S, Senini S: Daily versus weekly azithromycin in cystic fibrosis patients. Eur Respir J 2007;30:487-495.

-23 Courtney JM, Bradley J, McCaughan J: Predictors of mortality in adults with cystic fibrosis. Pediatr Pulmonol 2007;42:525-532.

24 Navarro J, Rainisio M, Harms HK: Factors associated with poor pulmonary function: cross-sectional analysis of data from the ERCF. European Epidemiologic Registry of Cystic Fibrosis. Eur Respir J 2001;18:298305.

-25 Saiman L, Anstead M, Mayer-Hamblett N: Effect of azithromycin on pulmonary function in patients with cystic fibrosis uninfected with Pseudomonas aeruginosa: a randomized controlled trial. JAMA 2010;303: 1707-1715.
26 Bush A, Rubin BK: Macrolides as biological response modifiers in cystic fibrosis and bronchiectasis. Semin Respir Crit Care Med 2003;24:737-748.

27 Giamarellos-Bourboulis EJ: Macrolides beyond the conventional antimicrobials: a class of potent immunomodulators. Int J Antimicrob Agents 2008;31:12-20.

28 Healy DP: Macrolide immunomodulation of chronic respiratory diseases. Curr Infect Dis Rep 2007;9:7-13.

29 Idris SF, Chilvers ER, Haworth C: Azithromycin therapy for neutrophilic airways disease: myth or magic? Thorax 2009;64:186189.

30 Tamaoki J: The effects of macrolides on inflammatory cells. Chest 2004;125:41S-50S.

31 Cole PJ: Inflammation: a two-edged sword the model of bronchiectasis. Eur J Respir Dis Suppl 1986;147:6-15.

32 Hanania NA: Targeting airway inflammation in asthma: current and future therapies. Chest 2008;133:989-998.

>33 Seemungal TA, Wilkinson TM, Hurst JR: Long-term erythromycin therapy is associated with decreased chronic obstructive pulmonary disease exacerbations. Am J Respir Crit Care Med 2008;178:1139-1147.

34 Altenburg J, de Graaff CS, van der Werf TS, Boersma WG: Immunomodulatory effects of macrolide antibiotics - part 1: biological mechanisms. Respiration 2011;81:67-74.

\$3 Ray WA, Murray KT, Meredith S: Oral erythromycin and the risk of sudden death from cardiac causes. N Engl J Med 2004;351: 1089-1096.

36 Wallace MR, Miller LK, Nguyen MT: Ototoxicity with azithromycin. Lancet 1994;343: 241.

37 Nicotra MB: Bronchiectasis. Semin Respir Infect 1994;9:31-40.

38 van Haren EH, Mannes GP: Diagnosis and treatment of bronchiectasis (in Dutch). Ned Tijdschr Geneeskd 2004;148:120-125.

39 Cohen M, Sahn SA: Bronchiectasis in systemic diseases. Chest 1999;116:1063-1074.

40 Barker AF: Bronchiectasis. N Engl J Med 2002;346:1383-1393.

-41 Pasteur MC, Helliwell SM, Houghton SJ: An investigation into causative factors in patients with bronchiectasis. Am J Respir Crit Care Med 2000;162:1277-1284.

42 Suhs RH, Dowling HF, Jackson GG: Hypogammaglobulinemia with chronic bronchitis or bronchiectasis: treatment of five patients with long-term antibiotic therapy. Arch Intern Med 1965;116:29-38.

43 Koh YY, Lee MH, Sun YH: Effect of roxithromycin on airway responsiveness in children with bronchiectasis: a double-blind, placebo-controlled study. Eur Respir J 1997;10: 994-999.

44 Tsang KW, Ho PI, Chan KN: A pilot study of low-dose erythromycin in bronchiectasis. Eur Respir J 1999;13:361-364.
45 Yalcin E, Kiper N, Ozcelik U: Effects of claritromycin on inflammatory parameters and clinical conditions in children with bronchiectasis. J Clin Pharm Ther 2006;31:49-55.

46 Cymbala AA, Edmonds LC, Bauer MA: The disease-modifying effects of twice-weekly oral azithromycin in patients with bronchiectasis. Treat Respir Med 2005;4:117-122.

47 Davies G, Wilson R: Prophylactic antibiotic treatment of bronchiectasis with azithromycin. Thorax 2004;59:540-541.

-48 National Collaborating Centre for Chronic Conditions: Chronic obstructive pulmonary disease: National clinical guideline on management of chronic obstructive pulmonary disease in adults in primary and secondary care. Thorax 2004;59(suppl 1):1-232.

49 Siempos II, Dimopoulos G, Korbila IP: Macrolides, quinolones and amoxicillin/clavulanate for chronic bronchitis: a meta-analysis. Eur Respir J 2007;29:1127-1137.

50 Black P, Staykova T, Chacko E: Prophylactic antibiotic therapy for chronic bronchitis. CochraneDatabaseSystRev2003;CD004105.

51 Banerjee D, Khair OA, Honeybourne D: The effect of oral clarithromycin on health status and sputum bacteriology in stable COPD. Respir Med 2005;99:208-215.

52 Macrolide Azithromycin to Prevent Rapid Worsening of Symptoms Associated With Chronic Obstructive Pulmonary Disease. http://clinicaltrials.gov (identifier: NCT00325897).

53 Kunisaki KM, Niewoehner DE: Antibiotic prophylaxis for chronic obstructive pulmonary disease: resurrecting an old idea. Am J Respir Crit Care Med 2008;178:1098-1099.

54 Desrosiers MY, Kilty SJ: Treatment alternatives for chronic rhinosinusitis persisting after ESS: what to do when antibiotics, steroids and surgery fail. Rhinology 2008;46:3-14.

55 Hashiba M, Baba S: Efficacy of long-term administration of clarithromycin in the treatment of intractable chronic sinusitis. Acta Otolaryngol Suppl 1996;525:73-78.

56 Kimura N, Nishioka K, Nishizaki K: Clinical effect of low-dose, long-term roxithromycin chemotherapy in patients with chronic sinusitis. Acta Med Okayama 1997;51:33-37.

57 Suzuki H, Shimomura A, Ikeda K: Effects of long-term low-dose macrolide administration on neutrophil recruitment and IL-8 in the nasal discharge of chronic sinusitis patients. Tohoku J Exp Med 1997;182:115-124.

58 Cervin A, Wallwork B: Anti-inflammatory effects of macrolide antibiotics in the treatment of chronic rhinosinusitis. Otolaryngol Clin North Am 2005;38:1339-1350.

59 Yamada T, Fujieda S, Mori S: Macrolide treatment decreased the size of nasal polyps and IL-8 levels in nasal lavage. Am J Rhinol 2000;14:143-148.

60 Wallwork B, Coman W, Mackay-Sim A: A double-blind, randomized, placebo-controlled trial of macrolide in the treatment of chronic rhinosinusitis. Laryngoscope 2006; 116:189-193 
61 Cervin A, Kalm O, Sandkull P: One-year low-dose erythromycin treatment of persistent chronic sinusitis after sinus surgery: clinical outcome and effects on mucociliary parameters and nasal nitric oxide. Otolaryngol Head Neck Surg 2002;126:481-489.

62 Suzuki H, Ikeda K, Honma R: Prognostic factors of chronic rhinosinusitis under longterm low-dose macrolide therapy. ORL J Otorhinolaryngol Relat Spec 2000;62:121-127.

63 Chapman ID, Foster A, Morley J: The relationship between inflammation and hyperreactivity of the airways in asthma. Clin Exp Allergy 1993;23:168-171.

64 Jeffery PK: Remodeling in asthma and chronic obstructive lung disease. Am J Respir Crit Care Med 2001;164:S28-S38.

65 Amayasu H, Yoshida S, Ebana S: Clarithromycin suppresses bronchial hyperresponsiveness associated with eosinophilic inflammation in patients with asthma. Ann Allergy Asthma Immunol 2000;84:594-598.

-66 Beigelman A, Gunsten S, Mikols CL: Azithromycin attenuates airway inflammation in a noninfectious mouse model of allergic asthma. Chest 2009;136:498-506.

67 Ekici A, Ekici M, Erdemoglu AK: Effect of azithromycin on the severity of bronchial hyperresponsiveness in patients with mild asthma. J Asthma 2002;39:181-185.

68 Kamoi H, Kurihara N, Fujiwara H: The macrolide antibacterial roxithromycin reduces bronchial hyperresponsiveness and superoxide anion production by polymorphonuclear leukocytes in patients with asthma. J Asthma 1995;32:191-197.

69 Miyatake H, Taki F, Taniguchi H: Erythromycin reduces the severity of bronchial hyperresponsiveness in asthma. Chest 1991;99: 670-673.

70 Shimizu T, Kato M, Mochizuki H: Roxithromycin reduces the degree of bronchial hyperresponsiveness in children with asthma. Chest 1994;106:458-461.

71 Takizawa H, Desaki M, Ohtoshi T: Erythromycin and clarithromycin attenuate cytokine-induced endothelin-1 expression in human bronchial epithelial cells. Eur Respir J 1998; 12:57-63.

72 Spector SL: Troleandomycin: effectiveness in steroid dependent asthma and bronchitis. J Allergy Clin Immunol 1974;54:367-379.

73 Szefler SJ, Rose JQ, Ellis EF: The effect of troleandomycin on methylprednisolone elimination. J Allergy Clin Immunol 1980;66: 447-451.

74 Hill JM, Tattersfield AE: Corticosteroid sparing agents in asthma. Thorax 1995;50: 577-582.

75 Szefler SJ, Brenner M, Jusko WJ: Dose- and time-related effect of troleandomycin on methylprednisolone elimination. Clin Pharmacol Ther 1982;32:166-171.

-76 Zeiger RS, Schatz M, Sperling W: Efficacy of troleandomycin in outpatients with severe, corticosteroid-dependent asthma. J Allergy Clin Immunol 1980;66:438-446.
77 Wald JA, Friedman BF, Farr RS: An improved protocol for the use of troleandomycin (TAO) in the treatment of steroid-requiring asthma. J Allergy Clin Immunol 1986;78: 36-43.

78 Harris R, German D: The incidence of corticosteroid side effects in chronic steroid-dependent asthmatics on TAO (troleandomycin) and methylprednisolone. Ann Allergy 1989;63:110-111.

79 Ball BD, Hill MR, Brenner M: Effect of lowdose troleandomycin on glucocorticoid pharmacokinetics and airway hyperresponsiveness in severely asthmatic children. Ann Allergy 1990;65:37-45.

80 Kamada AK, Hill MR, Ikle DN: Efficacy and safety of low-dose troleandomycin therapy in children with severe, steroid-requiring asthma. J Allergy Clin Immunol 1993;91: 873-882.

81 Nelson HS, Hamilos DL, Corsello PR: A double-blind study of troleandomycin and methylprednisolone in asthmatic subjects who require daily corticosteroids. Am Rev Respir Dis 1993;147:398-404.

82 Evans DJ, Cullinan P, Geddes DM: Troleandomycin as an oral corticosteroid steroid sparing agent in stable asthma. Cochrane Database Syst Rev 2001;CD002987.

83 Garey KW, Rubinstein I, Gotfried MH: Long-term clarithromycin decreases prednisone requirements in elderly patients with prednisone-dependent asthma. Chest 2000; 118:1826-1827.

84 Sutherland ER, Martin RJ: Asthma and atypical bacterial infection. Chest 2007;132: 1962-1966.

85 Martin RJ, Kraft M, Chu HW: A link between chronic asthma and chronic infection. J Allergy Clin Immunol 2001;107:595-601.

86 Berkovich S, Millian SJ, Snyder RD: The association of viral and mycoplasma infections with recurrence of wheezing in the asthmatic child. Ann Allergy 1970;28:43-49.

87 Lieberman D, Lieberman D, Printz S: Atypical pathogen infection in adults with acute exacerbation of bronchial asthma. Am J Respir Crit Care Med 2003;167:406-410.

88 Seggev JS, Lis I, Siman-Tov R: Mycoplasma pneumoniae is a frequent cause of exacerbation of bronchial asthma in adults. Ann Allergy 1986;57:263-265.

89 Black PN, Scicchitano R, Jenkins CR: Serological evidence of infection with Chlamydia pneumoniae is related to the severity of asthma. Eur Respir J 2000;15:254-259.

90 Cook PJ, Davies P, Tunnicliffe W: Chlamydia pneumoniae and asthma. Thorax 1998;53: 254-259.

91 Cunningham AF, Johnston SL, Julious SA: Chronic Chlamydia pneumoniae infection and asthma exacerbations in children. Eur Respir J 1998;11:345-349.

92 MokJY, Waugh PR, Simpson H: Mycoplasma pneumonia infection: a follow-up study of 50 children with respiratory illness. Arch Dis Child 1979;54:506-511.
93 Sabato AR, Martin AJ, Marmion BP: Mycoplasma pneumoniae: acute illness, antibiotics, and subsequent pulmonary function. Arch Dis Child 1984;59:1034-1037.

\$4 Kraft M, Cassell GH, Pak J: Mycoplasma pneumoniae and Chlamydia pneumoniae in asthma: effect of clarithromycin. Chest 2002;121:1782-1788.

$\checkmark 95$ Black PN, Blasi F, Jenkins CR: Trial of roxithromycin in subjects with asthma and serological evidence of infection with Chlamydia pneumoniae. Am J Respir Crit Care Med 2001;164:536-541.

96 Hahn DL, Plane MB, Mahdi OS: Secondary outcomes of a pilot randomized trial of azithromycin treatment for asthma. PLoS Clin Trials 2006;1:e11.

97 Richeldi L, Ferrara G, Fabbri LM: Macrolides for chronic asthma. Cochrane Database Syst Rev 2005;CD002997.

$\checkmark 98$ Piacentini GL, Peroni DG, Bodini A: Azithromycin reduces bronchial hyperresponsiveness and neutrophilic airway inflammation in asthmatic children: a preliminary report. Allergy Asthma Proc 2007;28:194-198.

-99 Simpson JL, Powell H, Boyle MJ: Clarithromycin targets neutrophilic airway inflammation in refractory asthma. Am J Respir Crit Care Med 2008;177:148-155.

100 Cordier JF: Organising pneumonia. Thorax 2000;55:318-328.

101 Ichikawa Y, Ninomiya H, Katsuki M: Lowdose/long-term erythromycin for treatment of bronchiolitis obliterans organizing pneumonia (BOOP). Kurume Med J 1993; 40:65-67.

102 Stover DE, Mangino D: Macrolides: a treatment alternative for bronchiolitis obliterans organizing pneumonia? Chest 2005; 128:3611-3617.

103 Hotta M: Neutrophil chemotactic activity in cryptogenic organizing pneumonia and the response to erythromycin. Kurume Med J 1996;43:207-217.

104 Periti P, Mazzei T, Mini E: Adverse effects of macrolide antibacterials. Drug Saf 1993; 9:346-364.

105 Principi N, Esposito S: Comparative tolerability of erythromycin and newer macrolide antibacterials in paediatric patients. Drug Saf 1999;20:25-41.

106 Rubinstein E: Comparative safety of the different macrolides. Int $J$ Antimicrob Agents 2001;18(suppl 1):S71-S76.

107 Brown BA, Griffith DE, Girard W: Relationship of adverse events to serum drug levels in patients receiving high-dose azithromycin for mycobacterial lung disease. Clin Infect Dis 1997;24:958-964.

108 McGhan LJ, Merchant SN: Erythromycin ototoxicity. Otol Neurotol 2003;24:701702 .

109 Sacristan JA, Soto JA, de Cos MA: Erythromycin-induced hypoacusis: 11 new cases and literature review. Ann Pharmacother 1993;27:950-955. 
110 Swanson DJ, Sung RJ, Fine MJ: Erythromycin ototoxicity: prospective assessment with serum concentrations and audiograms in a study of patients with pneumonia. Am J Med 1992;92:61-68.

- 111 Uzun C, Koten M, Adali MK: Reversible ototoxic effect of azithromycin and clarithromycin on transiently evoked otoacoustic emissions in guinea pigs. J Laryngol Otol 2001;115:622-628.

112 Haydon RC, Thelin JW, Davis WE: Erythromycin ototoxicity: analysis and conclusions based on 22 case reports. Otolaryngol Head Neck Surg 1984;92:678-684.

-113 Tseng AL, Dolovich L, Salit IE: Azithromycin-related ototoxicity in patients infected with human immunodeficiency virus. Clin Infect Dis 1997;24:76-77.

-114 Simko J, Csilek A, Karaszi J: Proarrhythmic potential of antimicrobial agents. Infection 2008;36:194-206.

- 115 Owens RC Jr, Nolin TD: Antimicrobial-associated QT interval prolongation: pointes of interest. Clin Infect Dis 2006;43:16031611.

116 Volberg WA, Koci BJ, Su W: Blockade of human cardiac potassium channel human ether-a-go-go-related gene (HERG) by macrolide antibiotics. J Pharmacol Exp Ther 2002;302:320-327.

- 117 Paran Y, Mashav N, Henis O: Drug-induced torsades de pointes in patients aged 80 years or more. Anadolu Kardiyol Derg 2008;8: 260-265.

-118 Shaffer D, Singer S, Korvick J: Concomitant risk factors in reports of torsades de pointes associated with macrolide use: review of the United States Food and Drug Administration Adverse Event Reporting System. Clin Infect Dis 2002;35:197-200.

-119 Inoue M, Farrell DJ, Kaneko K: Antimicrobial susceptibility of respiratory tract pathogens in Japan during PROTEKT years 1-5 (1999-2004). Microb Drug Resist 2008; 14:109-117.

120 Jacobs E, Dalhoff A, Korfmann G: Susceptibility patterns of bacterial isolates from hospitalised patients with respiratory tract infections (MOXIAKTIV Study). Int J Antimicrob Agents 2009;33:52-57.

121 Karlowsky JA, Lagace-Wiens PR, Low DE: Annual macrolide prescription rates and the emergence of macrolide resistance among Streptococcus pneumoniae in Canada from 1995 to 2005. Int J Antimicrob Agents 2009;34:375-379.

122 Pihlajamaki M, Kaijalainen T, Huovinen P: Rapid increase in macrolide resistance among penicillin non-susceptible pneumococci in Finland, 1996-2000. J Antimicrob Chemother 2002;49:785-792.
123 Niki Y, Hanaki H, Matsumoto T: Nationwide surveillance of bacterial respiratory pathogens conducted by the Japanese Society of Chemotherapy in 2007: general view of the pathogens' antibacterial susceptibility. J Infect Chemother 2009;15:156-167.

124 Riedel S, Beekmann SE, Heilmann KP: Antimicrobial use in Europe and antimicrobial resistance in Streptococcus pneumoniae. Eur J Clin Microbiol Infect Dis 2007;26: 485-490.

125 Barkai G, Greenberg D, Givon-Lavi N: Community prescribing and resistant Streptococcus pneumoniae. Emerg Infect Dis 2005;11:829-837.

126 Bergman M, Huikko S, Huovinen P: Macrolide and azithromycin use are linked to increased macrolide resistance in Streptococcus pneumoniae. Antimicrob Agents Chemother 2006;50:3646-3650.

127 Garcia-Rey C, Aguilar L, Baquero F: Importance of local variations in antibiotic consumption and geographical differences of erythromycin and penicillin resistance in Streptococcus pneumoniae. J Clin Microbiol 2002;40:159-164.

128 Malhotra-Kumar S, Lammens C, Martel A: Oropharyngeal carriage of macrolide-resistant viridans group streptococci: a prevalence study among healthy adults in Belgium. J Antimicrob Chemother 2004;53: 271-276.

129 Perez-Trallero E, Vicente D, Montes M: High proportion of pharyngeal carriers of commensal streptococci resistant to erythromycin in Spanish adults. J Antimicrob Chemother 2001;48:225-229.

130 Lonks JR, Garau J, Medeiros AA: Implications of antimicrobial resistance in the empirical treatment of community-acquired respiratory tract infections: the case of macrolides. J Antimicrob Chemother 2002; 50(suppl S2):87-92.

131 Hansen CR, Pressler T, Hoiby N: Longterm, low-dose azithromycin treatment reduces the incidence but increases macrolide resistance in Staphylococcus aureus in Danish CF patients. J Cyst Fibros 2009;8:58-62.

132 Phaff SJ, Tiddens HA, Verbrugh HA: Macrolide resistance of Staphylococcus aureus and Haemophilus species associated with long-term azithromycin use in cystic fibrosis. J Antimicrob Chemother 2006;57:741746

133 Tramper-Stranders GA, Wolfs TF, Fleer A: Maintenance azithromycin treatment in pediatric patients with cystic fibrosis: longterm outcomes related to macrolide resistance and pulmonary function. Pediatr Infect Dis J 2007;26:8-12.

$\checkmark 134$ Kasahara K, Kita E, Maeda K: Macrolide resistance of Streptococcus pneumoniae isolated during long-term macrolide therapy: difference between erythromycin and clarithromycin. J Infect Chemother 2005;11: 112-114.
135 Bishai W: A testament to sustained macrolide efficacy. Clin Infect Dis 2003;36:935936.

136 Nuermberger E, Bishai WR: The clinical significance of macrolide-resistant Streptococcus pneumoniae: it's all relative. Clin Infect Dis 2004;38:99-103.

137 Rothermel CD: Penicillin and macrolide resistance in pneumococcal pneumonia: does in vitro resistance affect clinical outcomes? Clin Infect Dis 2004;38(suppl 4):S346-S349.

138 Ewig S, Ruiz M, Torres A: Pneumonia acquired in the community through drugresistant Streptococcus pneumoniae. Am J Respir Crit Care Med 1999;159:1835-1842.

139 Lonks JR, Garau J, Gomez L: Failure of macrolide antibiotic treatment in patients with bacteremia due to erythromycin-resistant Streptococcus pneumoniae. Clin Infect Dis 2002;35:556-564.

140 Van Kerkhoven D, Peetermans WE, Verbist L: Breakthrough pneumococcal bacteraemia in patients treated with clarithromycin or oral beta-lactams. J Antimicrob Chemother 2003;51:691-696.

141 Griffith DE, Aksamit T, Brown-Elliott BA: An official ATS/IDSA statement: diagnosis, treatment, and prevention of nontuberculous mycobacterial diseases. Am J Respir Crit Care Med 2007;175:367-416.

142 Griffith DE, Brown-Elliott BA, Langsjoen B: Clinical and molecular analysis of macrolide resistance in Mycobacterium avium complex lung disease. Am J Respir Crit Care Med 2006;174:928-934.

143 Gordin FM, Sullam PM, Shafran SD: A randomized, placebo-controlled study of rifabutin added to a regimen of clarithromycin and ethambutol for treatment of disseminated infection with Mycobacterium avium complex. Clin Infect Dis 1999; 28:1080-1085.

144 Lam PK, Griffith DE, Aksamit TR: Factors related to response to intermittent treatment of Mycobacterium avium complex lung disease. Am J Respir Crit Care Med 2006;173:1283-1289.

145 Benson CA, Williams PL, Currier JS: A prospective, randomized trial examining the efficacy and safety of clarithromycin in combination with ethambutol, rifabutin, or both for the treatment of disseminated $M y$ cobacterium avium complex disease in persons with acquired immunodeficiency syndrome. Clin Infect Dis 2003;37:1234-1243.

146 Field SK, Cowie RL: Treatment of Mycobacterium avium-intracellulare complex lung disease with a macrolide, ethambutol, and clofazimine. Chest 2003;124:1482-1486.

147 Wallace RJ Jr, Brown BA, Griffith DE: Initial clarithromycin monotherapy for $\mathrm{Myco-}$ bacterium avium-intracellulare complex lung disease. Am J Respir Crit Care Med 1994;149:1335-1341. 